\title{
Nanotechnology as a Platform for Thermal Therapy of Prostate Cancer
}

\author{
Wei Wang', Guihai Chen ${ }^{3 *}$ and Yongping Chen ${ }^{2-4 *}$ \\ ${ }^{1}$ Department of Urology, the Second People's Hospital of Hefei, Hefei 234000, Anhui, PR China \\ 2Department of Biomedical Engineering, Johns Hopkins University, 720 Rutland Avenue, Baltimore, Maryland 21205, USA \\ ${ }^{3}$ Department of Neurology, the First People's Hospital of Chenzhou, Chenzhou 423000, Hunan, PR China \\ ${ }^{4}$ Washington Biotechnology Inc, 6200 Seaforth Street, Baltimore, Maryland 21224, USA
}

\begin{abstract}
Over the past several years, there has been increasing research and clinical interest in using nanotechnology for cancer therapy. Nanoparticle provides tremendous potential for future medical therapy. Besides targeting cancer cells, delivering and releasing drugs in a regulated manner, the specificity of nanoparticles is what makes thermal therapy as attractive as a cancer therapy. In this mini review, we discuss some of the recent advances of nanotechnology for thermal therapy of prostate cancer.
\end{abstract}

Keywords: Cancer therapy; Nanoparticle; Thermal therapy; Prostate cancer

Since 2005, cancer has become the leading cause of death in individuals under age 85 in the USA [1] and Prostate cancer (PCa) is the most common non-skin cancer diagnosed in the USA [2]. It is estimated that approximately 238,590 new cases and 29,720 prostate cancerrelated deaths will occur in the United States in 2013. Prostate cancer is now the second leading cause of cancer death in men, exceeded only by lung cancer. It accounts for $28 \%$ of all male cancers and $10 \%$ of male cancer-related deaths The PSA (prostate specific antigen) test has been used for initial diagnosis of disease, and monitored for recurrence after initial therapy and for prognosis of outcomes. Diagnosis of prostate has been substantially improved with the combined use of digital rectal examination, measurement of serum PSA levels and transrectal ultrasound [3]. Nearly $90 \%$ of men with prostate cancer were diagnosed with clinically localization [4]. Therefore, an early intervention to the disease could be more appropriate for such patients.

Currently chemotherapy is a preferred modality in the treatment of prostate cancer, [5] for example; docetaxel and mitoxantrone are considered first-line chemotherapeutic options in patients with hormone-refractory prostate cancer (HRPC) [6]. But modest drug response and significant toxicity by conventional methods of administration limit their efficacy. For these issues, targeted cancer therapies offer significant therapeutic benefits over existing chemotherapy regimens since the drug is preferentially delivered to the cancer tissue. The side effects associated with chemotherapy can be minimized by targeted drug delivery. Nanoparticles have large flexibility in engineering design with sustained-release characteristics are the most promising candidates as drug delivery carriers. Over past a few years, researchers have developed different types of nanoparticles for treatment of cancer [7]. For targeting of prostate cancer, one such antigen is the prostate specific membrane antigen (PSMA) [8,9]. PSMA is a protein abundantly expressed on the surface of prostate cancer cells, metastatic disease and the hormone-refractory form. Anti-PSMA mAbs that bind the extracellular PSMA domain were used in targeting cells for prostate cancer therapy and imaging by several research groups [10-12]. Not limiting to antibody, aptamers, also known as chemical antibodies have recently been demonstrated as ideal candidates for molecular targeting applications. Many groups developed aptamers conjugated with nanoparticles for prostate cancer therapy and molecular imaging. For example, Chu et al. [13] used A9 RNA aptamer: gelonin as conjugates to target and destroy prostatespecific membrane antigen (PSMA)-positive PCa cells. Dhar et al. [14] reported the use of A10 PSMA Apt conjugation with PLGA for targeted delivery of cisplatin to prostate cancer cells. Javier et al. [15] developed aptamer-based gold nanoparticles as contrast agents for imaging of PSMA (+) prostate cancer cells.

After we mentioned the strategy of targeting for prostate cancer above, we will discuss the treatment of prostate cancer. As low-risk clinically localized disease, the treatments of prostate cancer include watchful waiting, radical prostatectomy, external beam radiation therapy (RT) and interstitial RT (brachytherapy), freezing the prostate (cryotherapy), and androgen deprivation therapy (ADT). And for prostate cancer recurrence, the patients would be offered radiation therapy, androgen deprivation therapy (ADT), thermal therapy and others. Among of these, thermal therapy was very interesting and promising for prostate cancer locally therapy.

Thermal therapy (also called hyperthermia or thermotherapy) is a type of cancer treatment in which body tissue is exposed to high temperatures (up to $113^{\circ} \mathrm{F}$ ). Research has shown that high temperatures can be used to damage and kill cancer cells without damage to normal tissue [16]. Thermal therapy may shrink tumors by killing cancer cells and damaging proteins and structures within the cells [17]. Several methods of hyperthermia are currently under study, including local, regional, and whole-body hyperthermia. Recently, nanoparticles for local hyperthermal show tremendous promise in the safe and effective transducers for cancer therapy. Ji et al. [18] summarized carbon nanotubes as carriers for drug delivery and thermal therapies. Kennedy et al. [19] reviewed gold-nanoparticle-mediated thermal therapies. Kumar and Mohammad [20] reported magnetic nanomaterials for controlled drug delivery and hyperthermia-based therapy. Here, we highlighted three types of nanoparticles (carbon nanotubes, gold

*Corresponding authors: Yongping Chen, Department of Biomedical Engineering, Johns Hopkins University, 720 Rutland Avenue, Baltimore, Maryland 21205, USA, E-mail: yongpingchen686@gmail.com

Guihai Chen, Department of Neurology, the First People's Hospital of Chenzhou, Chenzhou 423000, Hunan, PR China, E-mail: chenguihai1964@163.com

Received June 29, 2013; Accepted July 03, 2013; Published July 05, 2013

Citation: Wang W, Chen G, Chen Y (2013) Nanotechnology as a Platform for Thermal Therapy of Prostate Cancer. J Mol Biomark Diagn 4: e117. doi:10.4172/2155-9929.1000e117

Copyright: $\odot 2013$ Wang W, et al. This is an open-access article distributed under the terms of the Creative Commons Attribution License, which permits unrestricted use, distribution, and reproduction in any medium, provided the original author and source are credited 
Citation: Wang W, Chen G, Chen Y (2013) Nanotechnology as a Platform for Thermal Therapy of Prostate Cancer. J Mol Biomark Diagn 4: e117. doi:10.4172/2155-9929.1000e117

nanoparticles, and magnetic nanoparticles) for prostate cancer thermal therapy.

Carbon nanotubes (CNT) as a class of nanomaterials holds great potential for various biomedical applications including extrinsically activated hyperthermia for prostate cancer therapy. Fisher et al. [21] demonstrated the capability of multiwalled carbon nanotubes (MWNTs) coupled with laser irradiation to enhance treatment of Human prostate cancer. Ghosh et al. [22] reported DNA-encases multiwalled carbon nanotubes (MWNTs) were used to safely eradicate prostate cancer in vivo following NIR irradiation of MWNTs. Despite these promising results, the toxicity of carbon nanotubes has been an important question in nanotechnology. CNTs from manufactured and combustion sources in the environment could have adverse effects on human health [23]. From this issue, gold nanoparticles are especially appealing due to bioinertness and biocompatibility for biomedical use. For thermal therapy of prostate cancer, Stern et al. [24] used laser activated gold nanoshells for selective prostate cancer thermal ablation. Gobin et al. [25] demonstrated elective photo-thermal destruction of prostate cancer upon application of prostate-specific EphrinA1conjugated gold nanoshells with the NIR laser irradiation. Normally, the size of gold nanoshells is more than $100 \mathrm{~nm}$ which is not suitable for in vivo application. Therefore, a gold nanorod is more attractive to researchers due to small size, easily surface function and with tunable plasmon resonance (SPR) in NIR region. As agents for prostate cancer therapy, Gormley et al. [26] evaluated gold nanorods conjugated with the cyclic RGD fK peptide for prostate cancer treatment. In addition, thermotherapy using magnetic nanoparticles represents another interesting area of magnetically mediated hyperthermia for prostate cancer treatment. Johannsen et al. [27] analyzed the effects of thermotherapy using magnetic nanoparticles combined with external radiation on prostate cancer and demonstrated this technique was feasible for prostate cancer treatment. Further, morbidity and quality of life were investigated during thermotherapy using magnetic nanoparticles in locally recurrent prostate cancer, the results showed interstitial heating using magnetic nanoparticles was feasible and well tolerated in patients [28]. These promising results show nanoparticlesmediated thermal therapy can be as a minimally invasive method for hyperthermia treatment of prostate cancer.

In this mini review, we collected some examples where nanoparticles were employed to induce localized heating for thermal therapy of prostate cancer. We hope that readers will find them beneficial to their works including molecular targeting.

\section{References}

1. Jemal A, Murray T, Ward E, Samuels A, Tiwari RC, et al. (2005) Cancer Statistics, 2005. CA Cancer J Clin 55: 10-30.

2. Jemal A, Siegel R, Ward E, Murray T, Xu J, et al. (2007) Cancer statistics. CA Cancer J Clin 57: 43-66

3. Caplan A, Kratz A (2002) Prostate-specific antigen and the early diagnosis of prostate cancer. Am J Clin Pathol 117 Suppl S104-8.

4. Gleave ME, Coupland D, Drachenberg D, Cohen L, Kwong S, et al. (1996) Ability of serum prostate-specific antigen levels to predict normal bone scans in patients with newly diagnosed prostate cancer. Urology 47: 708-712.

5. Gilliqan T, Kantoff PW (2002) Chemotherapy for prostate cancer. Urology 60: 94-100.

6. Mechels J, Montemurro T, Murray N, Kollmannsberger C, Chi KN (2006) First and second-line chemotherapy with docetaxel or mitoxantrone in patients with hormone-refractory prostate cancer. Cancer 106: 1041-1046.
7. Peer D, Karp JM, Hong S, Farokhzad OC, Margalit R, et al. (2007) Nanocarriers as an emerging platform for cancer therapy. Nat Nanotechnol 2: 751-760.

8. Chang SS, Gaudin PB, Reuter VE, Heston W, Margalit R (2000) Prostatespecific membrane antigen: Present and future application. Urology 55: 622629.

9. Fair WR, GIsraeli RS, Heston WDW (1997) Prostate-specific membrane antigen. Prostate 32: 140-148.

10. Sanna V, Pintus G, Bandiera P, Anedda R, Punzoni S, et al. (2011) Development of polymeric microbubbles targeted to prostate-specific membrane antigen as prototype of novel ultrasound contrast agents. Mol Pharm 8: 748-757.

11. Liu J, Kopecková $P$, Bühler $P$, Wolf $P$, Pan $H$, et al. (2009) Biorecognition and subcellular trafficking of HPMA copolymer-anti-PSMA antibody conjugates by prostate cancer cells. Molecular Pharmaceutics 6: 959-970.

12. Anil KP, Andrzej M, James B, Thommey PT, Neil HB, et al. (2004) Synthesis and in vitro testing of J591 antibody-dendrimer conjugates for targeted Prostate Cancer Therapy. Bioconjugate Chem 15: 1174-1181.

13. Chu TC, Marks JW, Lavery LA, Faulkner S, Rosenblum MG, et al. (2006) Aptamer:toxin conjugates that specifically target prostate tumor cells. Cancer Res 66: 5989-5992.

14. Dhar S, Gu FX, Langer R, Farokhzad OC, Lippard SJ (2008) Targeted delivery of cisplatin to prostate cancer cells by aptamer functionalized $\mathrm{Pt}(\mathrm{IV})$ prodrugPLGA-PEG nanoparticles. Proc Natl Acad Sci U S A 105: 17356-17361.

15. Javier DJ, Nitin N, Levy M, Ellington A, Richards-Kortum R (2008) AptamerTargeted Gold Nanoparticles As Molecular-Specific Contrast Agents for Reflectance Imaging. Bioconjugate Chem 19: 1309-1312.

16. Zee JVD (2002) Heating the patient: a promising approach? Annals of Oncology 13: $1173-1184$

17. Hildebrandt B, Wust P, Ahlers O, Dieing A, Sreenivasa G, et al. (2002) The cellular and molecular basis of hyperthermia. Crit Rev Oncol Hematol 43 33-56.

18. Ji SR, Liu C, Zhang b, Yang Feng, Xu Jin, et al. (2010) Carbon nanotubes in cancer diagnosis and therapy. Biochimt Biophys Acta 1806: 29-35.

19. Kennedy LC, Bickford LR, Lewinski NA, Coughlin AJ, Hu Y, et al. (2011) A new era for cancer treatment: gold-nanoparticle-mediated thermal therapies. Small 7: 169-183.

20. Kumar CSSR, Mohammad F (2011) Magnetic nanomaterials for hyperthermiabased therapy and controlled drug delivery. Adv Drug Deliv Rev 63: 789-808.

21. Fisher JW, Sarkar S, Buchanan CF, Szot CS, Whitney J, et al. (2010) Photothermal Response of Human and Murine Cancer Cells to Multiwalled Carbon Nanotubes after Laser Irradiation. Cancer Res 70: 9855-9864.

22. Ghosh S, Dutta S, Gomes E, Carroll D, Agostino RD, et al. (2009) Increased Heating Efficiency and Selective Thermal Ablation of Malignant Tissue with DNA-Encased Multiwalled Carbon Nanotubes. ACS Nano 3: 2667-2673.

23. Lam CW, James JT, McCluskey R, Arepalli S, Hunter RL (2006) A review of carbon nanotube toxicity and assessment of potential occupational and environmental health risks. Crit Rev Toxicol 36: 189-217.

24. Stern JM, Stanfield J, Kabbani W, Hsieh JT, Cadeddu J (2008) Selective Prostate Cancer Thermal Ablation With Laser Activated Gold Nanoshells. J Urol 179: 748-753.

25. Gobin AM, Moon J, West J (2008) EphrinAl-targeted nanoshells for photothermal ablation of prostate cancer cells. Int J Nanomedicine 3: 351-358.

26. Gormley AJ, Malugin A, Ray A, Robinson R, Ghandehari H (2011) Biological evaluation of RGDfK-gold nanorod conjugates for prostate cancer treatment. J Drug Target 19: 915-924

27. Johannsen M, Thiesen B, Gneveckow U, Taymoorian k, Waldofner N, et al (2006) Thermotherapy Using Magnetic Nanoparticles Combined With External Radiation in an Orthotopic Rat Model of Prostate Cancer. Prostate 66: 97-104.

28. Johannsen M, Gneveckow U, Kaymoorian K, Thiesen B, Waldo N, et al. (2007) Morbidity and quality of life during thermotherapy using magnetic nanoparticles in locally recurrent prostate cancer: Results of a prospective phase I trial. Int J Hyperthermia 23: 315-323. 